Review

\title{
Future Directions for the Early Detection of Recurrent Breast Cancer
}

\author{
Erika J. Schneble ${ }^{1}$, Lindsey J. Graham ${ }^{1}$, Matthew P. Shupe ${ }^{1}$, Frederick L. Flynt ${ }^{1}$, Kevin P. Banks $^{1}$, Aaron D. \\ Kirkpatrick ${ }^{1}$, Aviram Nissan², Leonard Henry ${ }^{3}$, Alexander Stojadinovic ${ }^{4}$, Nathan M. Shumway ${ }^{1}$, Itzhak \\ Avital $^{4}$, George E. Peoples ${ }^{1}$, Robert F. Setlik ${ }^{1}$ \\ 1. San Antonio Military Medical Center (SAMMC), 3551 Roger Brooke Dr., Ft. Sam Houston, TX 78234, USA. \\ 2. Hadassah Medical Center, Kiryat Hadassah, POB 12000, Jerusalem, 91120, Israel. \\ 3. IU Health Goshen, 200 High Park Ave., Goshen, IN 46526, USA. \\ 4. Bon Secours Cancer Institute, 5855 Bremo Road, Richmond, VA 23226, USA.
}

$\triangle$ Corresponding author: Erika J. Schneble, Brooke Army Medical Center, Department of General Surgery, 3551 Roger Brooke Dr. Ft. Sam Houston, TX 78234. Office: 210-916-0439 Fax: 210-916-6658. Email: erika.j.schneble.mil@mail.mil.

(C) Ivyspring International Publisher. This is an open-access article distributed under the terms of the Creative Commons License (http://creativecommons.org/ licenses/by-nc-nd/3.0/). Reproduction is permitted for personal, noncommercial use, provided that the article is in whole, unmodified, and properly cited.

Published: 2014.03.16

\begin{abstract}
The main goal of follow-up care after breast cancer treatment is the early detection of disease recurrence. In this review, we emphasize the multidisciplinary approach to this continuity of care from surgery, medical oncology, and radiology. Challenges within each setting are briefly addressed as a means of discussion for the future directions of an effective and efficient surveillance plan of post-treatment breast cancer care.
\end{abstract}

Key words: Breast cancer; recurrence; adjuvant; surveillance; follow-up.

\section{Introduction}

Breast cancer is the most common malignancy in women with post-operative recurrence and metastases acting as the leading cause of breast-cancer associated mortality [1]. The number of patients in post-treatment surveillance programs is increasing secondary to the survival benefit of screening mammography and adjuvant therapies [2]. After curative primary treatment, approximately $15 \%$ of breast cancer survivors will develop a second breast malignancy within ten years [3]. This risk is further compounded by personal characteristics such as age and family history.

Despite the fact that randomized trials of intensive surveillance testing such as more frequent clinical examinations, biannual chest $\mathrm{x}$-rays, and bones scans have shown no mortality benefit [4-7], there has been a continued rise in financial cost and resource utilization devoted to developing more effective follow-up strategies to detect early recurrences [8]. In this paper, we will explore some of the new technologies being studied to improve breast cancer surveillance after primary treatment.

Current surveillance guidelines recommend mammography and clinical physical examinations [9, 10]. Unfortunately, this strategy may be less than ideal for a heterogeneous population. This review also explores a risk stratification strategy to allocate costlier yet more sensitive surveillance strategies. Future directions in breast cancer follow-up are examined within the settings of clinical, laboratory, and radiologic assessment. Emphasis is placed on detection of loco-regional or contralateral recurrence as detection of distant recurrence is classified as incurable without a correlated survival benefit $[10,11]$.

\section{Clinical Assessment}

Follow-up care after primary breast cancer treatment includes physical and psychological rehabilitation, assessment of treatment efficacy, and detection of recurrent or metachronous cancers. Current 
National Comprehensive Cancer Network (NCCN) guidelines recommend a history and physical examination every 4-6 months for 5 years, then every 12 months [10]. The American Society of Clinical Oncology (ASCO) $[9,11,12]$ recommends a careful history and physical examination every 3-6 months for the first three years, every 6-12 months for the $4^{\text {th }}$ and $5^{\text {th }}$ year and annually thereafter by a physician skilled in cancer surveillance and breast examinations.

Historically, most recurrences have been detected by the patient or by a clinician's physical exam [13]. The self-breast examination (SBE) and clinical breast examination (CBE) remain cost-effective methods intended to detect regional or contra-lateral breast cancer recurrence [14]. The value of clinical examination in detecting locoregional relapse is uncertain [15] although consistently valued by those producing current guidelines [9, 16]. A lack of survival advantage from CBE-detected recurrence has been suggested [17] in addition to the already significant limitations of the breast exam to include breast heterogeneity, examiner inexperience, and a lack of high specificity resulting in unnecessary biopsies [18].

The future of the CBE requires standardization to enhance sensitivity and specificity and minimize false positives. Ultimately, the development of better skills training and performance standards can enhance reliability of the CBE with multiple tools in development to achieve this goal. Two applications currently in practice include the use of silicone breast models for research and training and in-office breast ultrasound (US). Research of Mammacare ${ }^{\circledR}$ silicone breast models (Mammatech Corp., Gainesville, Fl, USA), a method for standardizing examinations of patients with various breast characteristics, has revealed the effects of tumor size and breast firmness on CBE precision [19-23]. Clinician training with these silicones breast models has also been shown to improve sensitivity [24]. In-office US may also be a useful adjunct to the physical exam although larger studies examining operator variability are needed [25-28]. The in-office US may clarify abnormal findings to eliminate biopsy of benign lesions. However, in-office breast US is not currently used for screening of the asymptomatic breast due to the interpretation skills required, poor visualization in patients with dense or nodular breasts, and the inability to reliably detect microcalcifications $[27,29,30]$.

In addition to silicone breast models and in-office US, other tools include tactile sensing technologies, electrical impedance scanning (EIS), and diffuse optical spectroscopy (DOS). Specific tactile sensing instruments include the piezoelectric finger (PEF) [31], the SureTouch Visual Mapping System (Medical Tactile, Inc.) [32, 33], and the Robotic Tactile
Breast Mass Identifier (Robo-Tac-BMI) [34] where capacitive sensors utilized to standardize quantitative information are intended to improve a physician's examination [34]. Although an early study demonstrates Robo-Tac-BMI's enhanced ability to detect cancer by sensing the elasticity of breast tissues, further testing of this technology is needed [31]. EIS utilizes differences between the electrical properties of malignant and normal breast cancer tissue. However, EIS requires the ability of the clinician to deliver a consistent and reproducible examination [35]. Further research is needed to ascertain the actual sensitivity of EIS $[36,37]$. DOS bases utility on the theory that malignant tissue reflects light of different intensities, although this technique is still in the earliest stages of research [38]. Overall, future research employing examination of asymptomatic patients with novel tools and technologies requires standardized research and reporting methods by multicenter trials prior to implementation in practice.

The future of clinical assessment may simply be the modification of performance standards compounded with better skills training. However, research funding is increasingly being dedicated to devising novel adjuncts to the clinical examination in order to address the challenging issue of over-diagnosis. With health care dollars limited and the need for services expanding, resources should be spent prudently. Although new approaches and technologies have great potential to dramatically change current standard of care, additional training and evaluation to ensure standardization of use and examination reproducibility in clinical practice is pivotal [39].

\section{Laboratory Assessment}

Guidelines for routine follow-up in asymptomatic patients do not recommend the use of complete blood counts, chemistry panels, and tumor markers [9]. The future of laboratory workup to detect relapse may instead exist in defining individual risk assessment. Given the heterogeneity of the disease, the challenge has become to personalize cancer care to best formulate an efficient treatment plan for each individual patient. Aside from deciding which women will benefit from cytotoxic chemotherapy, this treatment plan may also include defining the frequency and duration of follow up care. It is becoming increasingly recognized that a certain proportion of patients are at risk for late recurrence of disease beyond 5 years and in some cases beyond 10 years, which has led to the study of longer durations of adjuvant hormonal therapy. Current methods for defining risk of recurrence include lymph node status, tumor size, tumor grade, estrogen receptor (ER) posi- 
tivity, and human epidermal growth factor receptor 2 (HER2) positivity in addition to patient factors such as age and comorbidities.

The emergence of non-clinical risk factors including the study of genetic heterogeneity in breast cancer may help to better predict disease behavior and patterns of recurrence. In 2000, Perou et al [40] described molecular portraits of breast cancer by analyzing gene expression patterns using fluorescently labeled complimentary DNA (cDNA) prepared from messenger RNA (mRNA) that had been isolated from cultured cell lines. The final result is a matrix that displays gene transcript levels below the mean, equal to the mean, or above the mean. Based on this data, we now have the ability to make biological interpretations regarding disease behavior based on these unique molecular portraits. In the human breast there are luminal epithelial cells and basal epithelial cells, each type expressing different genes [40]. Based on gene expression clusters, breast cancer can be classified into at least 4 biologic subtypes [41, 42]. These are listed in Table 1.

At the $12^{\text {th }}$ International Breast Cancer Conference in March 2011, the topic of defining breast cancer subtypes was addressed [43]. As gene arrays can be costly and time consuming because of the need to send tissue to specialized laboratories, clinicopathological criteria were developed. One development was the use of immunohistochemical (IHC) stains to define risk of recurrence. An IHC profile was developed using ER and progesterone receptor (PgR) expression, the detection or overexpression of the HER2 oncogene and Ki-67 labeling index or an alternate method of measure of proliferation such as tumor grade. The definitions for each profile are listed alongside the genetic characteristics in Table 1 . Though experts acknowledge that breast cancer is made up of several subtypes, the consequences and utility of classifying the disease into these subtypes is unclear.

There are a number of genetic assays that assist in predicting recurrence risk. These include Oncotype $\mathrm{DX}^{\mathrm{TM}}$, MammaPrint ${ }^{\circledR}$, PAM50 ${ }^{\mathrm{TM}}$ and others. Oncotype DX (Genomic Health, Inc., CA) uses reverse transcription polymerase chain reaction (RT-PCR) to measure expression of 21 genes and calculate a recurrence score from 0-100 that correlates with the risk of distant relapse within 10 years. At present, the test has only been validated in node-negative, ER positive tumors [44, 45]. In addition, though a higher recurrence score predicts worse prognosis, it also correlates with a better response to chemotherapy [46]. MammaPrint ${ }^{\circledR}$ (Agendia, Irvine, Ca and Amsterdam, The Netherlands) is a 70-gene microarray primarily detecting expression of genes responsible for proliferation, invasion, and angiogenesis. At present, it is intended for use in younger women (age 61 or under) with node-negative breast cancer that is $<5 \mathrm{~cm}$ and either estrogen receptor positive or negative [44]. This test categorizes tumors into one of two groups: low-risk and high risk, each corresponding to either a lower or higher chance of developing distant metastases at 10 years [47]. It has been studied in women who had not received any endocrine therapy or cytotoxic chemotherapy as well as in patients with 1-3 positive nodes who received appropriate therapy and may be better at predicting recurrence than clinical models used to predict recurrence [48]. It was designed mainly as a tool to identify patients most likely to benefit from chemotherapy. The PAM50/Breast Bioclassifier ${ }^{\mathrm{TM}}$ (University Genomics, Inc.) is an assay that uses quantitative RT-PCR of 50 genes to classify breast cancers into the subtypes discussed above (see Table 1). It can provide prognostic information on any breast cancer subtype regardless of hormone receptor status.

Table I: Four biologic subtypes of breast cancer based on gene expression. FISH: fluorescence in situ hybridization.

\begin{tabular}{|c|c|c|c|}
\hline & Genetic characteristics & IHC Profile & Clinical characteristics \\
\hline \multirow[t]{3}{*}{ Luminal A } & \multirow{2}{*}{$\begin{array}{l}\text { High expression of ESR1 (ER), PGR (PR) as well as genes associated } \\
\text { with ER activation. }\end{array}$} & ER and/or PgR positive & Lower grade tumors \\
\hline & & HER2 negative & Best outcomes \\
\hline & Expression of keratins 8 and 18 & Ki-67 low $(<14 \%)$ & May relapse beyond 5 years \\
\hline \multirow[t]{4}{*}{ Luminal B } & \multirow{4}{*}{$\begin{array}{l}\text { Shares gene expression rates similar to both luminal A and ba- } \\
\text { sal-like subtypes. }\end{array}$} & ER and/or PgR positive & Higher grade tumors \\
\hline & & HER2 negative or amplified & Worse outcomes \\
\hline & & or over-expressed & Less responsive to endocrine therapy \\
\hline & & Ki-67 high & May relapse beyond 5 years \\
\hline \multirow[t]{3}{*}{ Basal-like } & \multirow{2}{*}{$\begin{array}{l}\text { Higher expression of keratin } 5 \text {, keratin } 6, c-k i t \text { and other genes. } \\
\text { Lower expression of fibronectin } 1 \text { and mucin } 1 \text {. }\end{array}$} & ER and PgR absent & "triple negative" \\
\hline & & HER2 negative & Poor prognosis \\
\hline & $\begin{array}{l}\text { Higher expression of genes related to cell growth and transcription } \\
\text { which indicate higher proliferation rates. }\end{array}$ & & $\begin{array}{l}\text { If disease relapses, it usually occurs within } \\
\text { first } 5 \text { years }\end{array}$ \\
\hline \multirow[t]{3}{*}{ Her2 enriched } & \multirow{2}{*}{$\begin{array}{l}\text { Express ERBB2 (HER2) as well as higher expression rates of MDR1, } \\
\text { S100 calcium binding protein P, fatty acid synthase, fibronectin 1, } \\
\text { syndecan } 1 .\end{array}$} & ER and PgR absent & $1 / 3$ of these will NOT be HER 2 \\
\hline & & $\begin{array}{l}\text { HER2 amplified or } \\
\text { over-expressed }\end{array}$ & $\begin{array}{l}\text { over-expressed or amplified, but will have } \\
\text { defining gene expression profile }\end{array}$ \\
\hline & \multicolumn{2}{|l|}{ Lower expression of $c-k i t$ and $c-m y c$. } & $\begin{array}{l}\text { If disease relapses, it usually occurs within } \\
\text { first } 5 \text { years }\end{array}$ \\
\hline
\end{tabular}


Voduc et al studied tumor samples from women with nonmetastatic breast cancer and classified them by IHC profile. Investigators then analyzed the incidence of local and regional recurrence. This study found that luminal A tumors had the lowest risk of local and regional relapse at 5 and 10 years and that HER2 enriched and basal-like tumors had the highest rates of relapse. An interesting finding in this study is that luminal $\mathrm{B}$ tumors (the second most common subtype behind luminal A) had an unexpectedly high rate of locoregional relapse [49]. The same year, Kennecke et al published a study examining the metastatic potential of breast cancer subtypes [50]. This study also used immunohistochemistry to classify tumors into subtypes. Of those patients with relapse, Basal-like and HER2 tumors almost always relapsed within the first 5 years whereas luminal subtypes experienced continued relapses between 5 and 15 years. Brain metastases were more often seen in HER2-enriched and basal-like subytpes whereas bone was the predominant metastatic site in luminal A, luminal B, and luminal HER2 subgroups.

Presently, genetic assays are employed to assist clinicians in counseling patients on whether the benefits of cytotoxic chemotherapy outweigh the risks. The future of such assays and biological classifications is open to a wide range of possibilities. An alternative to expensive genetic testing is to use IHC profiles to classify tumors into biologic subtypes, though this, too, has limitations such as inter-rater reliability.

\section{Circulating tumor cells}

Although advances are constantly being made, further research is needed to find the most efficient and accurate tools that will assist patients and their providers in formulating individualized treatment plans that maximize benefit while minimizing harm. Circulating tumor cells (CTC) hold promise as a sensitive and specific surrogate to provide crucial information on prognosis and treatment efficacy. The early dissemination of tumor cells from heterogeneous breast tumor, a complex and multi-factorial process [51], is often undetectable by current high-resolution imaging technologies. Only recently have clinical researchers been able to accurately and reproducibly detect occult tumor cells secondary to advances in isolation, enrichment, and detection methods [52].

The current practical application of CTC monitoring is within the metastatic setting [53]. Independent of other known prognostic factors, CTC burden has been shown to predict treatment efficacy, progression-free, and overall survival in patients with metastatic breast cancer prior to and at any point after initiation of systemic therapy [53-55]. The CellSearch system (Veridex, Warren, NJ) has gained Food and
Drug Administration (FDA) approval for targeted CTC detection in patients with metastatic breast and prostate cancer $[56,57]$.

Outside the metastatic setting, new research is emerging regarding the relevance of peripheral blood CTCs in high-risk, disease-free patients, who have completed primary curative therapy. Detection of CTCs in $10-60 \%$ of patients with non-metastatic breast cancer has been reported via various detection assays including density-gradient separation and subsequent cytokeratin immunostaining [58-60], cytokeratin-19 mRNA amplification [61-63], HER2 immunostaining [64], and the CellSearch method [65-67]. Here, the quantitative response of CTC (increasing, decreasing, or marginal change) before, during, and after adjuvant chemotherapy has shown significant correlation with relapse-free survival non-metastatic breast cancer patients [68]. Studies are also revealing the prognostic importance of CTC quantification in patients with non-metastatic breast cancer prior to neoadjuvant or adjuvant therapies. The presence of one or more circulating tumor cells is shown to predict early recurrence and decreased survival in chemo-naive patients with non-metastatic breast cancer [69]. Quantifying CTC in this manner may allow for an effective monitoring surrogate [70] that results in new therapeutic and surveillance concepts beyond the metastatic setting [51].

In contrast to mammography and clinical examination, routine laboratory evaluation is not currently recommended in the asymptomatic patient. However, the utility of laboratory testing may be to define risk assessment given the heterogeneity of breast cancer. As research continues, these biologic technologies hold promise in development of a highly personalized approach in cancer care.

\section{Radiology Assessment}

Mammography is proven to detect breast cancer at an early stage and reduce mortality when combined with the appropriate treatment [71, 72]. However, mammography has limitations to include decreased sensitivity in women with dense breasts and undesirable false positive rates $[71,73]$. Concerns related to radiation risk from mammography may also decrease patient compliance even though the overall radiation dose is low. Future methods of breast cancer screening and detection must demonstrate increased sensitivity and specificity while being non-invasive, low cost, and have a low radiation burden. Future models will incorporate appropriate patient risk assessment models to develop a tailored imaging strategy for each patient to maximize sensitivity and specificity while minimizing cost and radiation risk. The following is a discussion of some potential imaging 
modalities that may improve early detection of recurrent disease.

\section{Digital Breast Tomosynthesis}

Overlapping normal breast parenchyma is a frequent cause of false-positives in standard digital mammography. Digital breast tomosynthesis (DBT) acquires images in the same orientation as conventional digital mammography but can display images in a three-dimensional manner reducing the likelihood of breast tissue superimposition. Several clinical studies have confirmed DBT's ability to improve screening performance for asymptomatic women with increased cancer detection rates while lowering screening recall rates [74, 75]. Furthermore, several small studies have suggested that two-view DBT may prove to be an alternative to obtaining additional mammographic views in the diagnostic or symptomatic setting [76, 77]. The performance of DBT in both screening and diagnostic settings suggests it will improve the accuracy of surveillance in women with a personal history of breast cancer; however, appropriate clinical trials are necessary to evaluate this indication.

\section{Low-dose Mammography}

The risk of radiation induced cancer from mammography is exceedingly small compared to the proven mortality reduction of routine screening [78]. Nevertheless, concern remains about the radiation risks of mammography amongst patients and referring providers. To allay these concerns, without hindering the ability of detect cancer, low dose mammography units are utilized throughout Europe and the FDA recently approved a low-dose photon counting mammography unit in the United States. These units deliver half the absorbed dose of radiation to the breasts as a standard mammography machine [79]. Venturini and colleagues recently evaluated the efficacy of low-dose mammography with adjunct screening using either ultrasound or magnetic resonance imaging (MRI) in Europe. This resulted in a higher than expected cancer detection rate with good diagnostic performance and a low average glandular radiation dose to the breast [80]. A similar study evaluating a tailored imaging algorithm with low-dose mammography in the United States is a potential area of further investigation.

\section{Contrast Enhanced Mammography}

Contrast enhanced mammography is a technology recently FDA-approved in the US as an adjunct to standard mammography. In this technique an iodine-based contrast agent is injected intravenously and mammographic images obtained using either temporal contrast or dual energy techniques. Early studies demonstrate improved reader sensitivity and improved reader performance with the addition of contrast enhanced mammography to standard mammography and ultrasound in a diagnostic setting [81]. Other early studies show improved accuracy for the detection of breast cancer when compared with standard mammography. Limitations of this technique include the use of intravenous iodinated contrast and a slightly increased radiation dose compared to standard mammography. Contrast-enhanced mammography is similar to breast MRI in that it relies on tumor angiogenesis to detect cancer. Therefore, in theory it may perform similar to breast MRI in other settings such as high risk screening, as a means for early detection of breast cancer recurrence or monitoring response to neoadjuvant chemotherapy [81].

\section{Automated Whole-Breast Ultrasound}

Sonography is a widely available and inexpensive tool that does not require ionizing radiation or contrast injection. Studies demonstrate that hand-held sonography increases cancer detection rate in high risk populations, to include women with a personal history or breast cancer, but at the cost of increased recall examinations, biopsies, and recommendations for short term follow-ups [82]. Automated whole-breast ultrasound system is a new technology that performs two-dimensional ultrasound of both breasts utilizing robotic guidance of a standard ultrasound probe. This technique is hypothesized to provide a consistent high-quality study which eliminates user variability and decreases the time required for each examination. Currently automated whole-breast ultrasound used in conjunction with mammography has a similar cancer detection rate to hand-held ultrasound of 3.6 per 1000 with an acceptable positive predictive value for recommended biopsies of $38 \%$ [82]. Disadvantages of automated whole breast ultrasound include a limited ability to scan the posterior regions of large breasts, the time commitment required to review a large number of images by radiologists, and the need to recall patients for evaluation of indeterminate findings [82].

\section{Diffusion Weighted MRI of the Breast}

Diffusion weighted imaging is a magnetic resonance imaging technique that characterizes the mobility of water molecules; it is a currently established technique in neuroimaging that is rapid and does not require the administration of intravenous contrast. It shows potential as an adjunct tool with contrast enhanced breast MRI to reduce false positive findings and unnecessary biopsies. A meta-analysis demonstrated improved specificity of diffusion weighted 
breast imaging compared with dynamic contrast enhanced breast MR for differentiation of benign and malignant masses [83]. The American College of Radiology Imaging Network (ACRIN) is initiating a study to evaluate this indication for diffusion weighted imaging of the breast [84].

Diffusion weighted imaging may also play a role in evaluating patients' response to neoadjuvant chemotherapy. It shows similar accuracy to contrast enhanced MR for monitoring neoadjuvant chemotherapy; this may be of use for patients with impaired renal function [84]. The utility of diffusion weighted imaging for predicting response prior to initiation of chemotherapy is unclear at this time. Richard et al. demonstrated that pretreatment apparent diffusion coefficients (ADCs) from diffusion imaging could predict responders and non-responders to therapy when accounting for tumor subtypes (i.e. triple negative, HER2-enriched, luminal A, or luminal B) while other investigators showed no difference in pre-therapy ADC values for responders versus non-responders [79, 85-87]. Currently an ACRIN multi-institutional protocol is evaluating if changes in ADC values after each treatment cycle is predictive of pathologic complete response.

Diffusion weighted imaging may eventually be utilized as a non-contrast adjunct screening modality, particularly in patients with contraindications to intravenous contrast. This indication shows promise but is in the early stages of clinical investigation [84].

\section{Magnetic Resonance Spectroscopy of the Breast}

Magnetic resonance (MR) spectroscopy is a non-invasive and non-ionizing method of measuring chemical composition from a region in the body. By using choline-containing compounds as a biomarker of malignancy, spectroscopy can distinguish between benign and malignant lesions [88]. Multiple studies demonstrate improved specificity for distinguishing benign from malignant lesions when using MR spectroscopy in conjunction with contrast enhanced breast MR [88]. Early studies also show MR spectroscopy may play a role in assessing early response to neoadjuvant chemotherapy [89]. A multi-instititutional ACRIN study assessing the role of MRI in neoadjuvant chemotherapy is evaluating the effectiveness of MR spectroscopy after one cycle of chemotherapy.

\section{Diffuse Optical Imaging}

Diffuse optical imaging of the breast employs near infrared light to produce images and resolve spectroscopic information about the composition of tissues. It is a non-ionizing, low-cost, and non-invasive means to evaluate breast tissue without breast compression. Furthermore, it can measure physiologic properties of tissue such as hemoglobin concentration, blood oxygen saturation, and water/fat content [90]. Current investigations focus on the ability of diffuse optical imaging to identify and characterize breast masses as benign or malignant, detect cancer in dense breast tissue, and assess response to neoadjuvant therapy [91].

\section{Molecular Imaging}

Despite extensive research and development of novel molecular imaging agents, none are expected to be entering clinical use in the near future specifically for the role of surveillance of patients with a history of breast cancer. For the foreseeable future, fluorodeoxyglucose (FDG) positron-emission computed tomography (PET-CT) will continue to be instrumental in the imaging of evaluation of patient's with clinical or laboratory findings suspicious for recurrent disease. It's accuracy in this setting is well documented with the largest study to date demonstrating a sensitivity of $94 \%$ and specificity of $85 \%$ for an accuracy of $92 \%$. Compared with a conventional workup, the researchers found PET-CT's increased accuracy resulted in a change in management of more than half of the patients [92].

One unique exception to the utility of FDG PET-CT is in the scenario where recurrence is suspected, but the differential diagnosis includes the possibility of an active infectious or inflammatory process, something that can frequently be seen in association with ongoing cancer therapy. Activated granulocytes and macrophages have markedly increased metabolism and thus FDG uptake is increased, mimicking malignancy. In contrast, F-18 Fluorothymidine (FLT) is a PET radiolabeled biomarker for cell proliferation whose uptake is a direct reflection of thymidine kinase 1 (TK1) activity. TK1 is over-expressed in multiplying cells such as malignant breast tumors and their metastatic lesions. Thus, unlike FDG, FLT has the advantage of not accumulating in inflammation [93]. Therefore, FLT may offer a specific means of differentiating residual/recurrent disease from infection or bland inflammation.

Once recurrence is identified, the future focus of molecular imaging is to providing a non-invasive, whole-body means of characterizing the biologic nature of an individual's tumor burden in order to better select targeted therapies. Tumor phenotypes (receptor functional status) can shift over time, and thus recurrent breast cancer may have a different ER, PgR, and HER2 statuses than the patient's original primary tumor prompting the need for reassessment. While biopsy is often a simple means for re-assessing a solitary site of recurrent disease, tissue sampling of mul- 
tiple lesions is often not practical and some sites may be inaccessible. Additionally, tissue sampling of boney breast cancer metastases can be complicated by epitope loss related to decalcification, reducing the accuracy of histological analysis [93]. Fortunately, novel PET tracers are showing the ability to image the presence and thus may, in the future, be of critical value in determining which patients may benefit from various endocrine therapies (Table 2).

The estrogen receptor has been the focus of many investigations and fluoroestradiol (FES) seems to show the most promise. FES is a PET labeled estrogen analog that binds to estrogen receptors with high affinity and specificity. Several studies have demonstrated its tissue uptake correlates accurately with tumor ER expression when compared IHC [94]. Subsequently, FES-PET positivity has shown the ability to provide information similar to tissue ER expression, predicting which patients may benefit from endocrine therapy (Table 3).

About half of ER positive breast cancers are also positive for the expression of $\mathrm{PgR}$. Tumors that are both ER and PgR positive are more likely to respond to endocrine therapy in comparison to tumors that are ER positive, but $\mathrm{PgR}$ negative. Thus, knowledge of the $\mathrm{PgR}$ status is valuable for the optimal selection of therapy in patients with recurrent breast cancer. A compound still in preclinical trials, called fluoro furanyl norprogesterone (FFNP), has shown high affinity and selectivity for PgR [95]. In a small-animal study, Fowler and colleagues demonstrated its ability to identify early response to endocrine therapy prior to measurable changes in tumor size [96]. It is hoped that future studies may demonstrate the value of FFNP-PET in predicting the response to endocrine therapy.

Overexpression of the HER2 neu receptor is seen in nearly a third of breast cancers and plays a role in cell growth/survival. Like the steroid receptors, ER and $\mathrm{PgR}$, therapies have been targeted against it and thus tissue expression of HER2 is routinely assessed in clinical practice. Several single photon and positron-emitting radionuclides are under investigation for the in vivo evaluation of HER2 expression. One compound, the positron emitting 89Zr-trastuzumab (the same monoclonal antibody that comprises Herceptin) has been studied in 14 patients with metastatic breast cancer and was successful in identifying the majority of known lesions as well as some occult sites of disease [97]. Further trials will be necessary to assess the utility of this radiotracer in management of recurrent breast cancer.

Table 2: Novel PET tracers showing promise for use in patients with recurrent breast cancer.

\begin{tabular}{|c|c|}
\hline Radiotracer & Mechanism \\
\hline F18-fluorothymidine (FLT) & $\begin{array}{l}\text { Marker for cell proliferation, uptake reflects } \\
\text { TK1 activity }\end{array}$ \\
\hline F18- fluoroestradiol (FES) & $\begin{array}{l}\text { Distrobution \& intensity of uptake mimics +ER } \\
\text { lesions as assessed by IHC }\end{array}$ \\
\hline $\begin{array}{l}\text { F-18 furanyl norprogester- } \\
\text { one (FFNP) }\end{array}$ & $\begin{array}{l}\text { Shows high affinity \& selectivity for PgR as } \\
\text { confirmed by IHC/FISH }\end{array}$ \\
\hline 89Zr-trastuzumab & $\begin{array}{l}\text { Initial studies show ability to identify sites of } \\
\text { HER2 pos disease }\end{array}$ \\
\hline
\end{tabular}

Table 3: Studies demonstrating ability of FES-PET to predict response to endocrine therapies in patients with breast cancer.

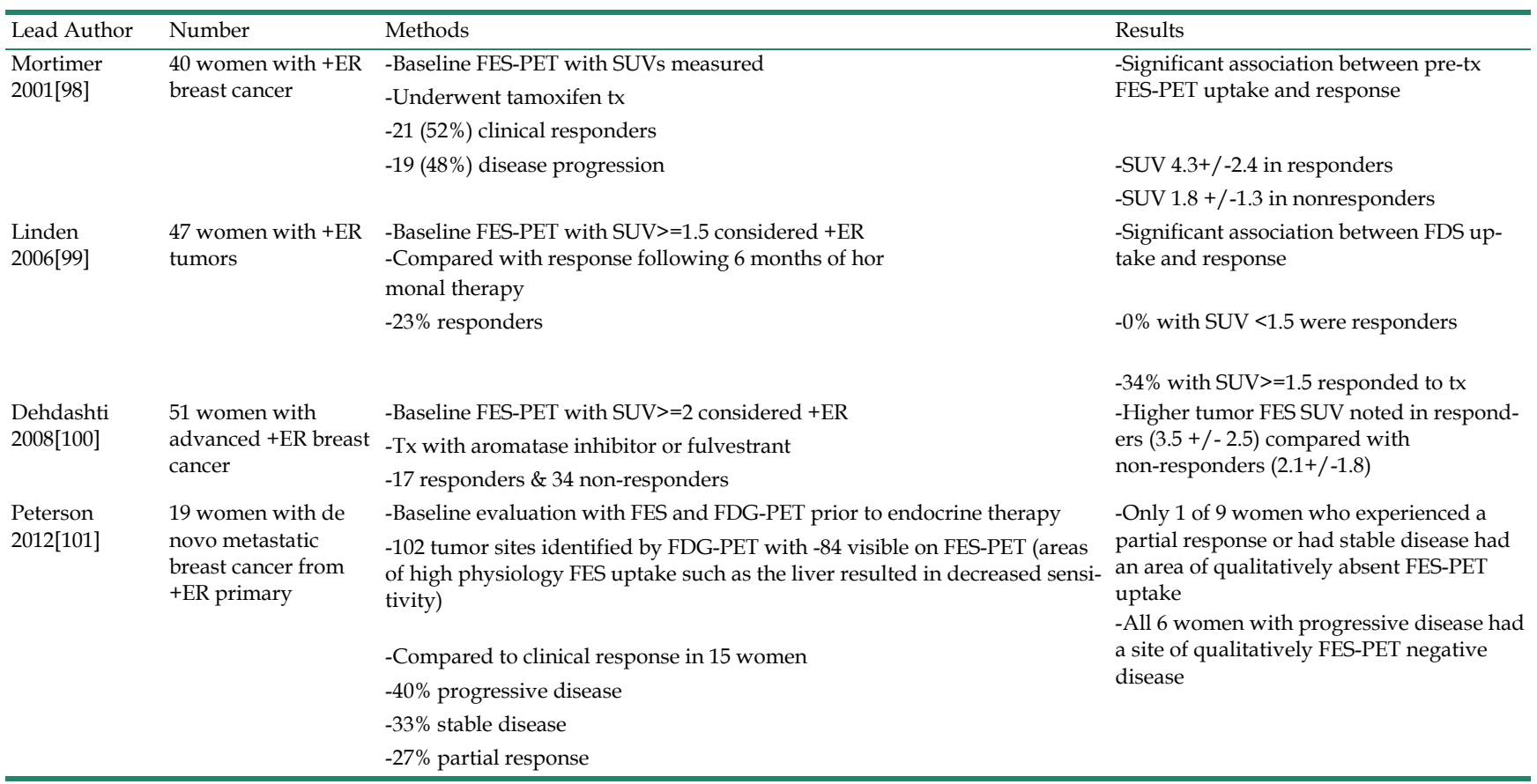




\section{Future of Imaging Modalities}

The imaging setting provides numerous although costly advanced techniques. Similar to the clinical and laboratory setting, identification of the appropriate population in addition to treatment and survival benefit need to be identified prior to common application of these new technologies. In the future, optimal breast imaging paradigms for screening or detection of recurrence may rely on one or more of these future imaging modalities. However, the literature and clinical experience of most practitioners suggests the optimal strategy will employ a highly personalized approach based upon risk stratification guiding appropriate selection of screening technologies.

\section{Conclusion}

As the prevalence of breast cancer rises, a dramatic increase in the number of breast cancer survivors will place clinical and financial demands on the long-term surveillance system [2]. Despite these challenges, evidence is mounting to suggest that disease relapse may be curable if diagnosed and treated early. We have explored several novel methods of clinical examination, laboratory testing, and advanced imaging which so far have failed to elicit a survival benefit. One difficulty has been trying to utilize newer technologies in a "one size fits all" prescription. This has led to an increase in resource utilization and expensive workups of false positive tests. Moving forward, developing testing models relevant to a risk stratification system for individualized care may help better elicit the clinical benefit of early detection. Clinicians should continue to be aware of the risk/benefit ratio of available options with future guidelines designed for optimal disease management that avoid both overand under-evaluation of a patient's disease status.

\section{Competing Interests}

The authors have declared that no competing interest exists.

\section{References}

1. American Cancer Society. Cancer Facts and Figures 2012. Atlanta GACS. 2012.

2. Parkin DM, Fernandez LM. Use of statistics to assess the global burden of breast cancer. The breast journal. 2006; 12 Suppl 1: S70-80. doi:10.1111/j.1075-122X.2006.00205.x.

3. Obedian E, Fischer DB, Haffty BG. Second malignancies after treatment of early-stage breast cancer: lumpectomy and radiation therapy versus mastectomy. J Clin Oncol. 2000; 18: 2406-12.

4. Gulliford T, Opomu M, Wilson E, Hanham I, Epstein R. Popularity of less frequent follow up for breast cancer in randomised study: initial findings from the hotline study. Bmj. 1997; 314: 174-7.

5. Rosselli Del Turco M, Palli D, Cariddi A, Ciatto S, Pacini P, Distante V. Intensive diagnostic follow-up after treatment of primary breast cancer. A randomized trial. National Research Council Project on Breast Cancer follow-up. JAMA. 1994; 271: 1593-7.

6. Palli D, Russo A, Saieva C, Ciatto S, Rosselli Del Turco M, Distante V, et al. Intensive vs clinical follow-up after treatment of primary breast cancer: 10-year update of a randomized trial. National Research Council Project on Breast Cancer Follow-up. JAMA. 1999; 281: 1586. doi:j1t0505 [pii].

7. Kokko R, Hakama M, Holli K. Follow-up cost of breast cancer patients with localized disease after primary treatment: a randomized trial. Breast Cancer Res Treat. 2005; 93: 255-60. doi:10.1007/s10549-005-5199-2.

8. Mapelli V, Dirindin N, Grilli R. Economic evaluation of diagnostic follow-up after primary treatment for breast cancer. Results of the Working Group on Economic-Organizational Aspects of Follow-up. Ann Oncol. 1995; 6 Suppl 2: 61-4.

9. Khatcheressian JL, Hurley P, Bantug E, Esserman LJ, Grunfeld E, Halberg F, et al. Breast cancer follow-up and management after primary treatment: American Society of Clinical Oncology clinical practice guideline update. J Clin Oncol. 2013; 31: 961-5. doi:10.1200/JCO.2012.45.9859.

10. NCCN Clinical Practice Guidelines in Oncology: Breast Screening and Diagnosis. National Comprehensive Cancer Network. 2013; Version 1.2013.

11. Khatcheressian JL, Wolff AC, Smith TJ, Grunfeld E, Muss HB, Vogel VG, et al. American Society of Clinical Oncology 2006 update of the breast cancer follow-up and management guidelines in the adjuvant setting. Journal of clinical oncology : official journal of the American Society of Clinical Oncology. 2006; 24: 5091-7. doi:JCO.2006.08.8575 [pii]10.1200/JCO.2006.08.8575.

12. Khatcheressian J, Swainey C. Breast cancer follow-up in the adjuvant setting. Curr Oncol Rep. 2008; 10: 38-46.

13. Schapira DV, Urban N. A minimalist policy for breast cancer surveillance. JAMA. 1991; 265: 380-2.

14. Lu WL, Jansen L, Post WJ, Bonnema J, Van de Velde JC, De Bock GH. Impact on survival of early detection of isolated breast recurrences after the primary treatment for breast cancer: a meta-analysis. Breast cancer research and treatment. 2009; 114: 403-12. doi:10.1007/s10549-008-0023-4.

15. Montgomery DA, Krupa K, Cooke TG. Follow-up in breast cancer: does routine clinical examination improve outcome? A systematic review of the literature. Br J Cancer. 2007; 97: 1632-41. doi:10.1038/sj.bjc.6604065.

16. Bevers TB, Anderson BO, Bonaccio E, Buys S, Daly MB, Dempsey PJ, et al. NCCN clinical practice guidelines in oncology: breast cancer screening and diagnosis. J Natl Compr Canc Netw. 2009; 7: 1060-96.

17. Montgomery DA, Krupa K, Jack WJ, Kerr GR, Kunkler IH, Thomas J, et al. Changing pattern of the detection of locoregional relapse in breast cancer: the Edinburgh experience. Br J Cancer. 2007; 96: 1802-7. doi:10.1038/sj.bjc.6603815.

18. Thomas DB, Gao DL, Ray RM, Wang WW, Allison CJ, Chen FL, et al. Randomized trial of breast self-examination in Shanghai: final results. J Natl Cancer Inst. 2002; 94: 1445-57.

19. McDermott MM, Dolan NC, Rademaker A. Effect of breast-tissue characteristics on the outcome of clinical breast examination training. Academic medicine : journal of the Association of American Medical Colleges. 1996; 71: 505-7.

20. McDermott MM, Dolan NC, Huang J, Reifler D, Rademaker AW. Lump detection is enhanced in silicone breast models simulating postmenopausal breast tissue. Journal of general internal medicine. 1996; 11: 112-4.

21. Pilgrim C, Lannon C, Harris RP, Cogburn W, Fletcher SW. Improving clinical breast examination training in a medical school: a randomized controlled trial. Journal of general internal medicine. 1993; 8: 685-8.

22. Campbell HS, Fletcher SW, Pilgrim CA, Morgan TM, Lin S. Improving physicians' and nurses' clinical breast examination: a randomized controlled trial. American journal of preventive medicine. 1991; 7: 1-8

23. Trapp MA, Kottke TE, Vierkant RA, Kaur JS, Sellers TA. The ability of trained nurses to detect lumps in a test set of silicone breast models. Cancer. 1999; 86: 1750-6.

24. Steiner E, Austin DF, Prouser NC. Detection and description of small breast masses by residents trained using a standardized clinical breast exam curriculum. Journal of general internal medicine. 2008; 23: 129-34. doi:10.1007/s11606-007-0444-5.

25. Law MT, Kollias J, Bennett I. Evaluation of Office Ultrasound Usage among Australian and New Zealand Breast Surgeons. World journal of surgery. 2013; 37: 2148-54. doi:10.1007/s00268-013-2076-8.

26. Lenz S. Breast ultrasound in office gynecology--ten years of experience. Ultraschall Med. 2011; 32 Suppl 1: S3-7. doi:10.1055/s-0029-1245426.

27. Edwards MJ. Office-based and intraoperative ultrasound enhance surgeon's care of breast disease patients. Annals of surgical oncology. 2003; 10: 201.

28. Kaufman CS, Jacobson L, Bachman B, Kaufman L. Intraoperative ultrasound facilitates surgery for early breast cancer. Annals of surgical oncology. 2002; 9: 988-93.

29. Dixon JM, Macaskill EJ. For the use of ultrasound by surgeons. Breast Cancer Online. 2007; 10: 3. doi:10.1017/S1470903107003501.

30. Athanasiou A, Tardivon A, Ollivier L, Thibault F, El Khoury C, Neuenschwander S. How to optimize breast ultrasound. European journal of radiology. 2009; 69: 6-13. doi:10.1016/j.ejrad.2008.07.034.

31. Xu X, Gifford-Hollingsworth C, Sensenig R, Shih WH, Shih WY, Brooks AD. Breast tumor detection using piezoelectric fingers: first clinical report. J Am Coll Surg. 2013; 216: 1168-73. doi:10.1016/j.jamcollsurg.2013.02.022.

32. Sarvazyan A, Hall TJ, Urban MW, Fatemi M, Aglyamov SR, Garra BS. An Overview of Elastography - an Emerging Branch of Medical Imaging. Current medical imaging reviews. 2011; 7: 255-82.

33. Wellman PS, Dalton EP, Krag D, Kern KA, Howe RD. Tactile imaging of breast masses: first clinical report. Archives of surgery. 2001; 136: 204-8.

34. Mojra A, Najarian S, Towliat Kashani SM, Panahi F, Tehrani MA. A novel robotic tactile mass detector with application in clinical breast examination. Minimally invasive therapy \& allied technologies : MITAT : official journal of 
the Society for Minimally Invasive Therapy. 2012; 21: $210-21$. doi:10.3109/13645706.2011.602087.

35. Kerne TE, Hartov A, Soho SK, Poplack SP, Paulsen KD. Imaging the breast with EIS: an initial study of exam consistency. Physiological measurement. 2002; 23: 221-36

36. Stojadinovic A, Nissan A, Shriver CD, Mittendorf EA, Akin MD, Dickerson V, et al. Electrical impedance scanning as a new breast cancer risk stratification tool for young women. J Surg Oncol. 2008; 97: 112-20. doi:10.1002/jso.20931.

37. Stojadinovic A, Moskovitz O, Gallimidi Z, Fields S, Brooks AD, Brem R, et al. Prospective study of electrical impedance scanning for identifying young women at risk for breast cancer. Breast Cancer Res Treat. 2006; 97: 179-89. doi:10.1007/s10549-005-9109-4.

38. Tromberg BJ, Cerussi A, Shah N, Compton M, Durkin A, Hsiang D, et al. Imaging in breast cancer: diffuse optics in breast cancer: detecting tumors in pre-menopausal women and monitoring neoadjuvant chemotherapy. Breast Cancer Res. 2005; 7: 279-85. doi:10.1186/bcr1358.

39. Murphy AM. Mammography screening for breast cancer: a view from 2 worlds. JAMA. 2010; 303: 166-7. doi:10.1001/jama.2009.1991.

40. Perou CM, Sorlie T, Eisen MB, van de Rijn M, Jeffrey SS, Rees CA, et al. Molecular portraits of human breast tumours. Nature. 2000; 406: 747-52. doi:10.1038/35021093

41. Sotiriou C, Neo S-Y, McShane LM, Korn EL, Long PM, Jazaeri AA, et al. Breast cancer classification and prognosis based on gene expression profiles from a population-based study. PNAS. 2002; 100: 10393-8.

42. Creighton CJ. The molecular profile of luminal B breast cancer. Biologics. 2012; 6: 289-97. doi:10.2147/BTT.S29923btt-6-289 [pii].

43. Goldhirsch A, Wood WC, Coates AS, Gelber RD, Thurlimann B, Senn HJ, et al. Strategies for subtypes--dealing with the diversity of breast cancer: highlights of the St. Gallen International Expert Consensus on the Primary Therapy of Early Breast Cancer 2011. Annals of oncology : official journal of the European Society for Medical Oncology / ESMO. 2011; 22: 1736-47. doi:10.1093/annonc/mdr304.

44. Arango BA, Rivera CL, Gluck S. Gene expression profiling in breast cancer. Am J Transl Res. 2013; 5: 132-8.

45. Habel LA, Shak S, Jacobs MK, Capra A, Alexander C, Pho M, et al. A population-based study of tumor gene expression and risk of breast cancer death among lymph node-negative patients. Breast cancer research : BCR. 2006; 8: R25.

46. Paik S, Tang G, Shak S, Kim C, Baker J, Kim W, et al. Gene expression and benefit of chemotherapy in women with node-negative, estrogen receptor-positive breast cancer. Journal of clinical oncology : official journal of the American Society of Clinical Oncology. 2006; 24: 3726-34. doi:10.1200/JCO.2005.04.7985.

47. van de Vijver MJ, He YD, van't Veer LJ, Dai H, Hart AA, Voskuil DW, et al. A gene-expression signature as a predictor of survival in breast cancer. N Engl J Med. 2002; 347: 1999-2009. doi:10.1056/NEJMoa021967347/25/1999 [pii].

48. Mook S, Schmidt MK, Viale G, Pruneri G, Eekhout I, Floore A, et al. The 70-gene prognosis-signature predicts disease outcome in breast cancer patients with 1-3 positive lymph nodes in an independent validation study. Breast cancer research and treatment. 2009; 116: 295-302. doi:10.1007/s10549-008-0130-2.

49. Voduc KD, Cheang MC, Tyldesley S, Gelmon K, Nielsen TO, Kennecke H. Breast cancer subtypes and the risk of local and regional relapse. Journal of clinical oncology : official journal of the American Society of Clinical Oncology. 2010; 28: 1684-91. doi:10.1200/JCO.2009.24.9284.

50. Kennecke H, Yerushalmi R, Woods R, Cheang MC, Voduc D, Speers CH, et al. Metastatic behavior of breast cancer subtypes. Journal of clinical oncology : official journal of the American Society of Clinical Oncology. 2010; 28: 3271-7. doi:10.1200/JCO.2009.25.9820.

51. Fehm T, Muller V, Alix-Panabieres C, Pantel K. Micrometastatic spread in breast cancer: detection, molecular characterization and clinical relevance. Breast Cancer Res. 2008; 10 Suppl 1: S1. doi:bcr1869 [pii]10.1186/bcr1869.

52. Jacob K, Sollier C, Jabado N. Circulating tumor cells: detection, molecular profiling and future prospects. Expert Rev Proteomics. 2007; 4: 741-56. doi:10.1586/14789450.4.6.741

53. Cristofanilli M, Budd GT, Ellis MJ, Stopeck A, Matera J, Miller MC, et al. Circulating tumor cells, disease progression, and survival in metastatic breast cancer. N Engl J Med. 2004; 351: 781-91. doi:10.1056/NEJMoa040766351/8/781 [pii].

54. Cristofanilli M, Hayes DF, Budd GT, Ellis MJ, Stopeck A, Reuben JM, et al. Circulating tumor cells: a novel prognostic factor for newly diagnosed metastatic breast cancer. J Clin Oncol. 2005; 23: 1420-30. doi:23/7/1420 [pii]10.1200/JCO.2005.08.140.

55. Hayes DF, Cristofanilli M, Budd GT, Ellis MJ, Stopeck A, Miller MC, et al. Circulating tumor cells at each follow-up time point during therapy of metastatic breast cancer patients predict progression-free and overall survival. Clin

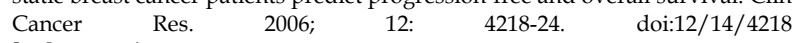
[pii]10.1158/1078-0432.CCR-05-2821.

56. Riethdorf S, Fritsche H, Muller V, Rau T, Schindlbeck C, Rack B, et al. Detection of circulating tumor cells in peripheral blood of patients with metastatic breast cancer: a validation study of the CellSearch system. Clin Cancer Res. 2007; 13: 920-8. doi:13/3/920 [pii]10.1158/1078-0432.CCR-06-1695.

57. Cohen SJ, Alpaugh RK, Gross S, O'Hara SM, Smirnov DA, Terstappen LW, et al. Isolation and characterization of circulating tumor cells in patients with metastatic colorectal cancer. Clin Colorectal Cancer. 2006; 6: 125-32. doi:S1533-0028(11)70253-5 [pii]10.3816/CCC.2006.n.029

58. Pierga JY, Bonneton C, Vincent-Salomon A, de Cremoux P, Nos C, Blin N, et al. Clinical significance of immunocytochemical detection of tumor cells using digital microscopy in peripheral blood and bone marrow of breast cancer patients. Clin Cancer Res. 2004; 10: 1392-400.

59. Gaforio IJ, Serrano MJ, Sanchez-Rovira P, Sirvent A, Delgado-Rodriguez M, Campos M, et al. Detection of breast cancer cells in the peripheral blood is positively correlated with estrogen-receptor status and predicts for poor prognosis. Int J Cancer. 2003; 107: 984-90. doi:10.1002/ijc.11479.

60. Wiedswang G, Borgen E, Schirmer C, Karesen R, Kvalheim G, Nesland JM, et al. Comparison of the clinical significance of occult tumor cells in blood and bone marrow in breast cancer. Int J Cancer. 2006; 118: 2013-9. doi:10.1002/ijc.21576.

61. Benoy IH, Elst H, Philips M, Wuyts H, Van Dam P, Scharpe S, et al. Real-time RT-PCR detection of disseminated tumour cells in bone marrow has superior prognostic significance in comparison with circulating tumour cells in patients with breast cancer. Br J Cancer. 2006; 94: 672-80. doi:6602985 [pii]10.1038/sj.bjc.6602985.

62. Daskalaki A, Agelaki S, Perraki M, Apostolaki S, Xenidis N, Stathopoulos E, et al. Detection of cytokeratin-19 mRNA-positive cells in the peripheral blood and bone marrow of patients with operable breast cancer. Br J Cancer. 2009; 101: 589-97.

63. Ignatiadis M, Xenidis N, Perraki M, Apostolaki S, Politaki E, Kafousi M, et al. Different prognostic value of cytokeratin-19 mRNA positive circulating tumor cells according to estrogen receptor and HER2 status in early-stage breast cancer. J Clin Oncol. 2007; 25: 5194-202. doi:JCO.2007.11.7762 [pii]10.1200/JCO.2007.11.7762.

64. Wulfing P, Borchard J, Buerger H, Heidl S, Zanker KS, Kiesel L, et al. HER2-positive circulating tumor cells indicate poor clinical outcome in stage I to III breast cancer patients. Clin Cancer Res. 2006; 12: 1715-20. doi:12/6/1715 [pii]10.1158/1078-0432.CCR-05-2087.

65. Bidard FC, Saliba AE, Saias L, Degeorges A, Cremoux P, Viovy JL, et al. [Circulating tumor cells and breast cancer: detection techniques and clinical results]. Bull Cancer. 2009; 96: 73-86. doi:bdc.2008.0797 [pii]10.1684/bdc.2008.0797.

66. Muller V, Riethdorf S, Rack B, Janni W, Fasching PA, Solomayer E, et al. Prognostic impact of circulating tumor cells assessed with the CellSearch System and AdnaTest Breast in metastatic breast cancer patients: the DETECT study. Breast Cancer Res. 2012; 14: R118. doi:bcr3243 [pii]10.1186/bcr3243.

67. Pierga JY, Bidard FC, Mathiot C, Brain E, Delaloge S, Giachetti S, et al. Circulating tumor cell detection predicts early metastatic relapse after neoadjuvant chemotherapy in large operable and locally advanced breast cancer in a phase II randomized trial. Clin Cancer Res. 2008; 14: 7004-10. doi:14/21/7004 [pii]10.1158/1078-0432.CCR-08-0030.

68. Pachmann K, Dengler R, Lobodasch K, Frohlich F, Kroll T, Rengsberger M, et al. An increase in cell number at completion of therapy may develop as an indicator of early relapse: quantification of circulating epithelial tumor cells (CETC) for monitoring of adjuvant therapy in breast cancer. J Cancer Res Clin Oncol. 2008; 134: 59-65. doi:10.1007/s00432-007-0248-3.

69. Lucci A, Hall CS, Lodhi AK, Bhattacharyya A, Anderson AE, Xiao L, et al. Circulating tumour cells in non-metastatic breast cancer: a prospective study. Lancet Oncol. 2012; 13: 688-95. doi:S1470-2045(12)70209-7 [pii]10.1016/S1470-2045(12)70209-7.

70. Hoos A, Parmiani G, Hege K, Sznol M, Loibner H, Eggermont A, et al. A clinical development paradigm for cancer vaccines and related biologics. J

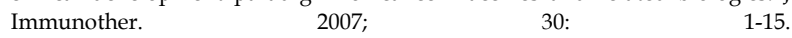
doi:10.1097/01.cji.0000211341.88835.ae00002371-200701000-00001 [pii].

71. Nelson HD, Tyne K, Naik A, Bougatsos C, Chan BK, Humphrey L, et al. Screening for breast cancer: an update for the U.S. Preventive Services Task Force. Annals of internal medicine. 2009; 151: 727-37, W237-42. doi:10.7326/0003-4819-151-10-200911170-00009.

72. Tabar L, Vitak B, Chen TH, Yen AM, Cohen A, Tot T, et al. Swedish two-county trial: impact of mammographic screening on breast cancer mortality during 3 decades. Radiology. 2011; 260: 658-63. doi:10.1148/radiol.11110469.

73. Pisano ED, Gatsonis C, Hendrick E, Yaffe M, Baum JK, Acharyya S, et al. Diagnostic performance of digital versus film mammography for breast-cancer screening. N Engl J Med. 2005; 353: 1773-83. doi:10.1056/NEJMoa052911.

74. Rafferty EA, Park JM, Philpotts LE, Poplack SP, Sumkin JH, Halpern EF, et al. Assessing radiologist performance using combined digital mammography and breast tomosynthesis compared with digital mammography alone: results of a multicenter, multireader trial. Radiology. 2013; 266: 104-13. doi:10.1148/radiol.12120674.

75. Skaane P, Gullien R, Bjorndal H, Eben EB, Ekseth U, Haakenaasen U, et al. Digital breast tomosynthesis (DBT): initial experience in a clinical setting. Acta Radiol. 2012; 53: 524-9. doi:ar.2012.120062 [pii]10.1258/ar.2012.120062.

76. Hakim CM, Chough DM, Ganott MA, Sumkin JH, Zuley ML, Gur D. Digital breast tomosynthesis in the diagnostic environment: A subjective side-by-side review. AJR Am J Roentgenol. 2010; 195: W172-6. doi:195/2/W172 [pii]10.2214/AJR.09.3244.

77. Zuley ML, Bandos AI, Ganott MA, Sumkin JH, Kelly AE, Catullo VJ, et al. Digital breast tomosynthesis versus supplemental diagnostic mammographic 
views for evaluation of noncalcified breast lesions. Radiology. 2013; 266: 89-95. doi:10.1148/radiol.12120552.

78. Feig SA, Hendrick RE. Radiation risk from screening mammography of women aged 40-49 years. Journal of the National Cancer Institute Monographs. 1997: 119-24.

79. Drukteinis JS, Mooney BP, Flowers CI, Gatenby RA. Beyond mammography: new frontiers in breast cancer screening. The American journal of medicine. 2013; 126: 472-9. doi:10.1016/j.amjmed.2012.11.025.

80. Venturini E, Losio C, Panizza P, Rodighiero MG, Fedele I, Tacchini S, et al. Tailored breast cancer screening program with microdose mammography, US, and MR Imaging: short-term results of a pilot study in 40-49-year-old women. Radiology. 2013; 268: 347-55. doi:10.1148/radiol.13122278.

81. Lobbes MB, Smidt ML, Houwers J, Tjan-Heijnen VC, Wildberger JE. Contrast enhanced mammography: techniques, current results, and potential indications. Clinical radiology. 2013; 68: 935-44. doi:10.1016/j.crad.2013.04.009.

82. Hooley RJ, Scoutt LM, Philpotts LE. Breast ultrasonography: state of the art. Radiology. 2013; 268: 642-59. doi:10.1148/radiol.13121606

83. Chen X, Li WL, Zhang YL, Wu Q, Guo YM, Bai ZL. Meta-analysis of quantitative diffusion-weighted MR imaging in the differential diagnosis of breast lesions. BMC cancer. 2010; 10: 693. doi:10.1186/1471-2407-10-693.

84. Partridge SC, McDonald ES. Diffusion weighted magnetic resonance imaging of the breast: protocol optimization, interpretation, and clinical applications. Magnetic resonance imaging clinics of North America. 2013; 21: 601-24. doi:10.1016/j.mric.2013.04.007.

85. Wu LM, Hu JN, Gu HY, Hua J, Chen J, Xu JR. Can diffusion-weighted MR imaging and contrast-enhanced MR imaging precisely evaluate and predict pathological response to neoadjuvant chemotherapy in patients with breast cancer? Breast cancer research and treatment. 2012; 135: 17-28. doi:10.1007/s10549-012-2033-5.

86. Richard R, Thomassin I, Chapellier M, Scemama A, de Cremoux P, Varna M, et al. Diffusion-weighted MRI in pretreatment prediction of response to neoadjuvant chemotherapy in patients with breast cancer. Eur Radiol. 2013. doi:10.1007/s00330-013-2850-x.

87. Hamaoka T, Madewell JE, Podoloff DA, Hortobagyi GN, Ueno NT. Bone imaging in metastatic breast cancer. Journal of clinical oncology : official journal of the American Society of Clinical Oncology. 2004; 22: 2942-53. doi:10.1200/JCO.2004.08.18122/14/2942 [pii].

88. Bolan PJ. Magnetic resonance spectroscopy of the breast: current status. Magnetic resonance imaging clinics of North America. 2013; 21: 625-39. doi:10.1016/j.mric.2013.04.008.

89. Argus A. Clinical Indications for breast MR. Applied Radiology. 2010; 39: 10-9.

90. Leff DR, Warren OJ, Enfield LC, Gibson A, Athanasiou T, Patten DK, et al. Diffuse optical imaging of the healthy and diseased breast: a systematic review. Breast cancer research and treatment. 2008; 108: 9-22. doi:10.1007/s10549-007-9582-z.

91. Tromberg BJ, Pogue BW, Paulsen KD, Yodh AG, Boas DA, Cerussi AE. Assessing the future of diffuse optical imaging technologies for breast cancer management. Medical physics. 2008; 35: 2443-51.

92. Champion L, Brain E, Giraudet AL, Le Stanc E, Wartski M, Edeline V, et al. Breast cancer recurrence diagnosis suspected on tumor marker rising: value of whole-body 18FDG-PET/CT imaging and impact on patient management. Cancer. 2011; 117: 1621-9. doi:10.1002/cncr.25727.

93. van Waarde A, Cobben DC, Suurmeijer AJ, Maas B, Vaalburg W, de Vries EF, et al. Selectivity of 18F-FLT and 18F-FDG for differentiating tumor from inflammation in a rodent model. J Nucl Med. 2004; 45: 695-700.

94. Peterson LM, Mankoff DA, Lawton T, Yagle K, Schubert EK, Stekhova S, et al. Quantitative imaging of estrogen receptor expression in breast cancer with PET and 18F-fluoroestradiol. J Nucl Med. 2008; 49: 367-74. doi:10.2967/jnumed.107.047506.

95. Dehdashti F, Laforest R, Gao F, Aft RL, Dence CS, Zhou D, et al. Assessment of progesterone receptors in breast carcinoma by PET with 21-18F-fluoro-16alpha,17alpha-[(R)-(1'-alpha-furylmethylidene)dioxy]-19-nor pregn- 4-ene-3,20-dione. Journal of nuclear medicine : official publication, Society of Nuclear Medicine. 2012; 53: 363-70. doi:10.2967/jnumed.111.098319.

96. Fowler AM, Chan SR, Sharp TL, Fettig NM, Zhou D, Dence CS, et al Small-animal PET of steroid hormone receptors predicts tumor response to endocrine therapy using a preclinical model of breast cancer. J Nucl Med. 2012; 53: 1119-26. doi:10.2967/jnumed.112.103465.

97. Dijkers EC, Oude Munnink TH, Kosterink JG, Brouwers AH, Jager PL, de Jong $\mathrm{JR}$, et al. Biodistribution of 89Zr-trastuzumab and PET imaging of HER2-positive lesions in patients with metastatic breast cancer. Clinical pharmacology and therapeutics. 2010; 87: 586-92. doi:10.1038/clpt.2010.12.

98. Mortimer JE, Dehdashti F, Siegel BA, Trinkaus K, Katzenellenbogen JA, Welch MJ. Metabolic flare: indicator of hormone responsiveness in advanced breast cancer. J Clin Oncol. 2001; 19: 2797-803.

99. Linden HM, Stekhova SA, Link JM, Gralow JR, Livingston RB, Ellis GK, et al. Quantitative fluoroestradiol positron emission tomography imaging predicts response to endocrine treatment in breast cancer. J Clin Oncol. 2006; 24: 2793-9. doi:10.1200/JCO.2005.04.3810.

100. Dehdashti F, Mortimer JE, Trinkaus K, Naughton MJ, Ellis M, Katzenellenbogen JA, et al. PET-based estradiol challenge as a predictive biomarker of response to endocrine therapy in women with estrogen-receptor-positive breast cancer. Breast Cancer Res Treat. 2009; 113: 509-17. doi:10.1007/s10549-008-9953-0.
101. Peterson LK, et al. Early results of an NCI-sponsored Phase II study of 18F-fluoroestradiol (FES) PET imaging of metastatic breast cancer (MBC). J Nucl Med. 2012; 53. 